\title{
Reconstrução palpebral com retalho de Fricke: relato de dois casos
}

\author{
Eyelid reconstruction with Fricke's flap: report of twocases
}

\author{
Guilherme Herzog Neto $^{1}$ \\ RobertoSebastiá ${ }^{2}$ \\ Giovanni André Pires Viana ${ }^{3}$ \\ Filipe Machado ${ }^{4}$
}

\section{RESUMO}

O câncer de pele é o tumor mais comum na espécie humana, sendo o carcinoma basocelular o de maior prevalência. Este trabalho relata dois casos recentes deste tipo de tumor, envolvendo tanto a pálpebra superior quanto a inferior em duas mulheres. O primeiro caso é de uma mulher de 72 anos de idade, amaurótica do olho direito, com comprometimento de aproximadamente $80 \%$ da pálpebra superior esquerda, $70 \%$ da pálpebra inferior esquerda e comprometimento da parede lateral da órbita, comprovado pela tomografia computadorizada. O exame anatomopatológico da peça cirúrgica revelou a presença de carcinoma basocelular invasivo, com margens livres. Foi feita reconstrução imediata com retalho de Fricke. $\mathrm{O}$ segundo caso é de senhora de 68 anos de idade, com história prévia de trauma na região periorbitária esquerda, apresentando edema e hiperemia palpebral, com aspecto brilhante, com perda dos cílios e pequena ulceração central, envolvendo aproximadamente $90 \%$ da pálpebra superior e $65 \%$ da pálpebra inferior esquerda, com comprometimento da parede lateral da órbita evidenciado na tomografia. $\mathrm{O}$ exame anatomopatológico da peça cirúrgica revelou a presença de carcinoma basocelular invasivo, com margens livres. Foi optado pela reconstrução imediata com retalho de Fricke. Os autores acreditam que apesar deste tipo de retalho não ser a primeira escolha na maioria das reconstruções palpebrais, não deveria ser negligenciado, pois em certos casos, tornar-se-ia a única opção viável.

Descritores: Carcinoma basocelular/cirurgia; Neoplasias cutâneas; Retalhos cirúrgicos; Pálpebras/cirurgia, Relatos de casos [tipo de publicação]

\section{INTRODUÇÃO}

O carcinoma basocelular é o tipo de câncer de pele mais comum, sendo que sua incidência na face, é maior na região nasal e áreas adjacentes a ela ${ }^{(1-2)}$.

Tanto a perda da pálpebra superior quanto da inferior, com a preservação do olho é uma ocorrência rara ${ }^{(3)}$, sendo uma das formas mais severas de deformidade com que um cirurgião pode se deparar.

Os autores apresentam dois casos de carcinoma basocelular invasivo, com comprometimento tanto da pálpebra superior, inferior e do rebordo orbitário, que foram tratados cirurgicamente através da técnica de rotação de retalho de Fricke.

\section{RELATO DOS CASOS}

\section{Caso 1}

Paciente branca, sexo feminino, 72 anos de idade, relata que há um ano 
notou uma 'espinha' no canto lateral do olho esquerdo, que não cicatrizava, com crescimento após a sua manipulação, procurando este serviço para tratamento (Figura 1). Ao exame observou-se uma lesão ulcerada, extensa, com bordas peroladas, envolvendo mais a pálpebra superior que a inferior. Foi observado também, que a paciente não apresentava visão no olho direito, devido a um trauma anterior (sic). Foram solicitados exames pré-operatórios de rotina e também uma tomografia computadorizada das órbitas com cortes coronais e axiais, que revelaram comprometimento da pálpebra superior e inferior, assim como invasão da parede lateral da órbita esquerda. A paciente foi submetida a ressecção da lesão sob anestesia geral, sendo retirado aproximadamente $80 \%$ da pálpebra superior e $70 \%$ da pálpebra inferior, com ressecção parcial da parede lateral da órbita esquerda. Durante a cirurgia, as margens da lesão foram examinadas através de biópsia de congelação, que certificou que elas estavam livres do tumor. Todo material foi enviado para exame anatomopatológico (parafina), que diagnosticou carcinoma basocelular invasivo, com todas as margens livres. A reconstrução das pálpebras foi realizada com a técnica de Fricke (Figura 2). Após quatro meses de cirurgia (Figura 3), esta paciente foi reoperada para melhora estética do canto lateral. Até o momento, esta paciente tem seguimento de um ano sem apresentar sinais de recidiva (figura 4).

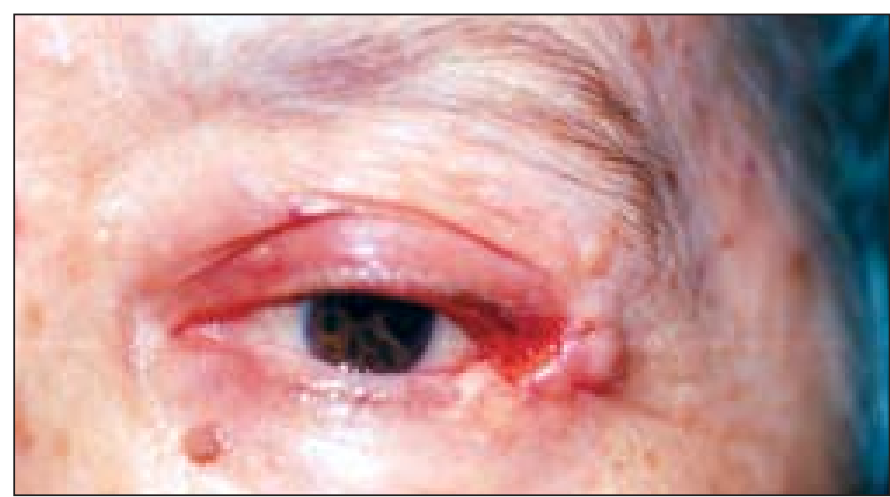

Figura 1 - Paciente com história de lesão ulcerada no canto lateral do olho esquerdo há um ano

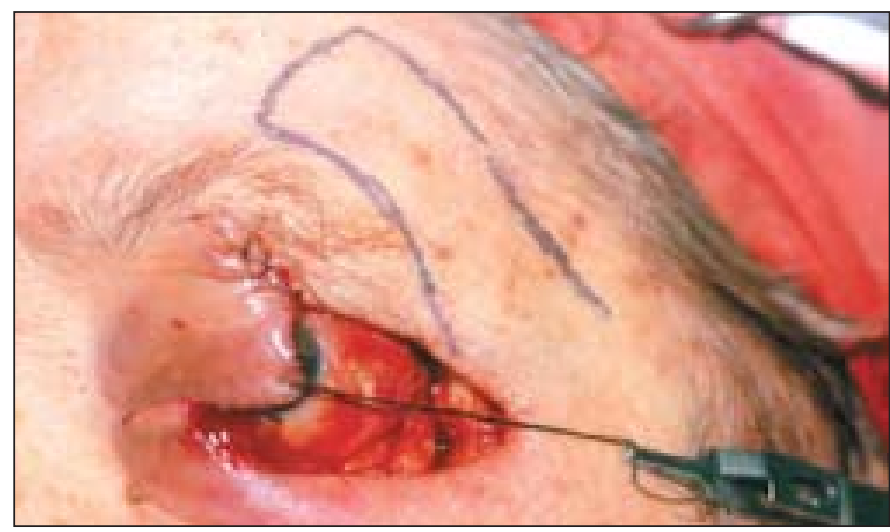

Figura 2 - Trans-operatório após a ressecção da lesão, com esquema para a confecção do retalho de Fricke

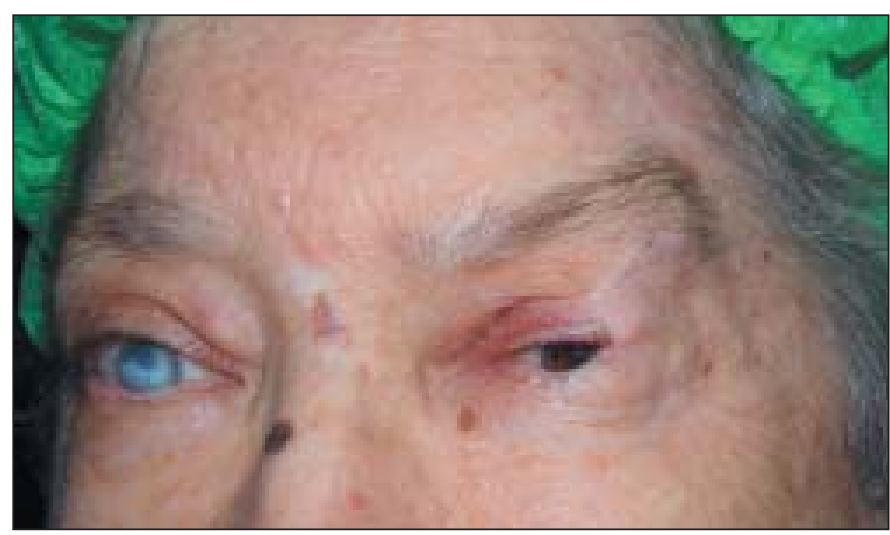

Figura 3 - Paciente no $4^{\circ}$ mês pós-operatório, retornando para novo tempo cirúrgico (melhora do canto lateral)

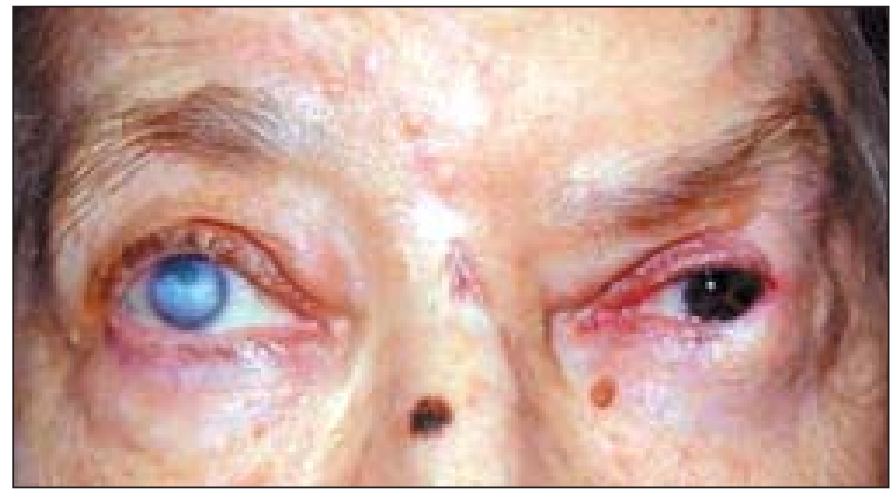

Figura 4 - Paciente um ano após a primeira cirurgia

\section{Caso 2}

Paciente branca, sexo feminino, 68 anos de idade, com história de trauma em face, principalmente na região periorbitária esquerda há dois anos, sendo atendida em outro serviço. Há um ano notou irritação no canto lateral esquerdo, sem melhora com o uso de medicação tópica (sic). A paciente referia piora do quadro com o passar dos meses, procurando nosso serviço para tratamento (Figura 5). Ao exame foi observado edema na pálpebra superior, apresentando-se com aspecto brilhante, hiperemiada, com perda dos cílios e pequena ulceração com pontos hemorrágicos. A pálpebra inferior estava comprometida na sua metade lateral. Observou-se também, que a paciente apresentava lesão do ramo frontal do nervo facial, provavelmente devido ao trauma de face. Foi solicitada avaliação clínica pré-operatória, bem como tomografia computadorizada das órbitas com cortes coronais e axiais. Esta revelou comprometimento tanto da pálpebra superior quanto da inferior e invasão superficial da parede lateral da órbita esquerda (Figura 6). A paciente foi submetida à ressecção da lesão sob anestesia geral, sendo retirado aproximadamente $90 \%$ da pálpebra superior e $65 \%$ da pálpebra inferior. Também foi ressecada parcialmente a parede lateral da órbita esquerda (Figura 7). Durante a cirurgia as margens foram examinadas através de biópsia de congelação, orientando o cirurgião quanto ao seu comprometimento ou não. Todo o material foi 
enviado para exame anatomopatológico, que diagnosticou carcinoma basocelular invasivo, com todas as margens livres. A reconstrução das pálpebras foi realizada através do uso do retalho de Fricke, sendo modificado seu desenho, devido as

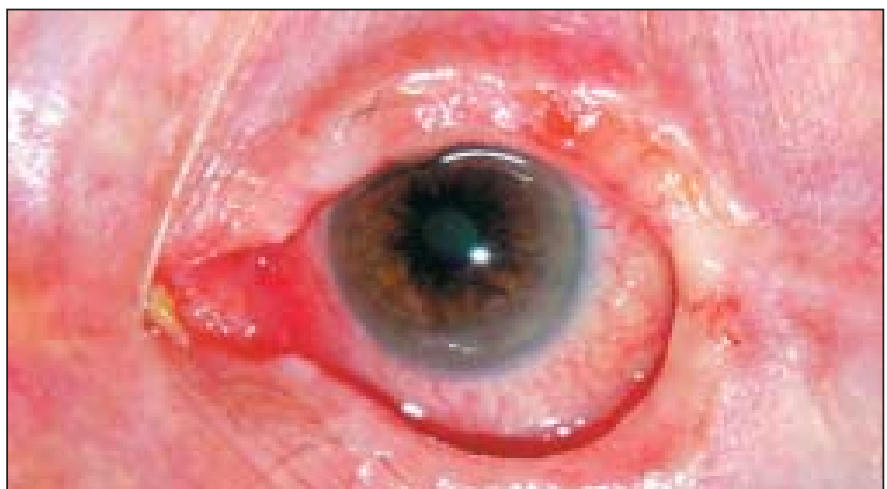

Figura 5 - Paciente com história de irritação no canto lateral do olho esquerdo há um ano

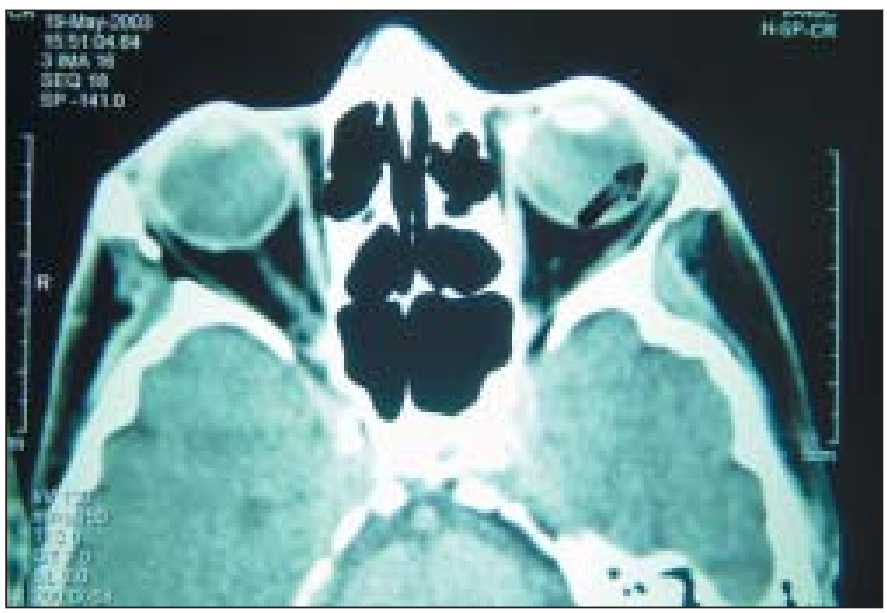

Figura 6 - Tomografia computadorizada demonstrando comprometimento superficial da parede lateral da órbita esquerda

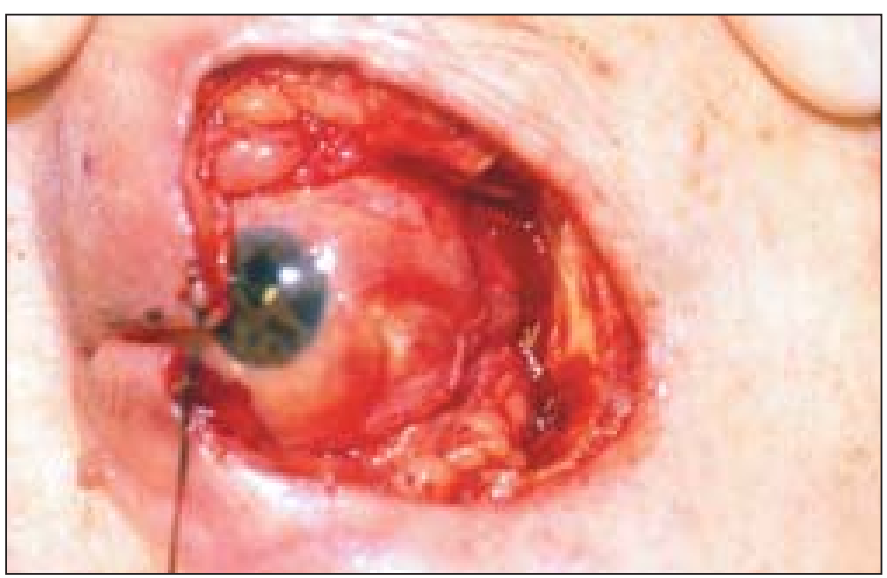

Figura 7 - Trans-operatório após a ressecção da lesão cicatrizes existentes na face da paciente (Figura 8). Após quatro meses de pós-operatório, esta paciente não apresenta sinal de recidiva (Figura 9).

\section{DISCUSSÃO}

O carcinoma basocelular é o tumor de pele mais comum, sendo maior sua incidência em pessoas de pele clara e expostas à radiação ultravioleta ${ }^{(1-2,4-6)}$. A distribuição deste tipo de lesão é de: $70 \%$ na pálpebra inferior, $20 \%$ no canto medial, $7 \%$ na pálpebra superior e $3 \%$ no canto lateral ${ }^{(1-2,7)}$. O método de tratamento depende do tamanho da lesão, sua localização e experiência do cirurgião, sendo que a taxa de cura em 5 anos varia entre 90 a 95\%, independentemente do tipo de tratamento escolhido nos tumores primários (cirurgia, crio-cirurgia, eletrodissecção e curetagem, cirurgia de Mohs e radioterapia) $)^{(1-2,4-5)}$.

O tratamento mais aceito é o cirúrgico, com a ressecção completa da lesão, com margens livres. $\mathrm{O}$ exame anatomopatológico ou histopatológico de rotina da peça cirúrgica é importante para a confirmação diagnóstica, definição do tipo histológico do tumor, avaliação da presença ou não de ulceração

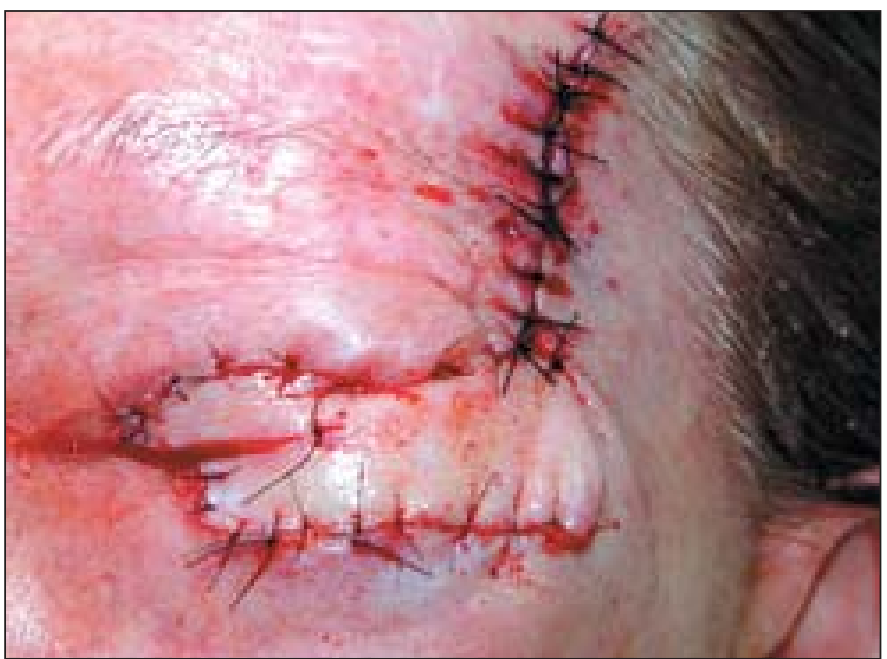

Figura 8 - Aspecto final da reconstrução após o término da cirurgia

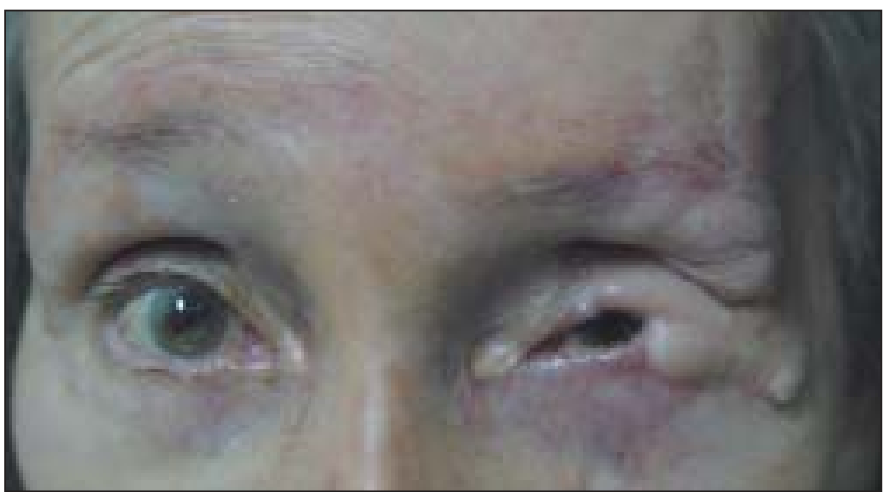

Figura 9 - Paciente no $4^{\circ}$ mês pós-operatório 
microscópica e do comprometimento das margens cirúrgicas da ressecção, assim como, a observação da distância entre o tumor e a margem de ressecção. A reconstrução imediata visa a preservação da função protetora das pálpebras e a função lacrimal, buscando sempre que possível uma reconstrução esteticamente aceitável, sem contudo comprometer a cirurgia oncológica.

A técnica de Fricke é descrita como retalho temporal da área supra-orbital da região frontal ${ }^{(1,3)}$. Nestes dois casos, o retalho foi usado para a reconstrução tanto da pálpebra superior quanto da inferior, sendo bipartido para se acomodar nesta posição. Este tipo de retalho fornece uma boa espessura para a pálpebra reconstruída, mas geralmente necessita de um segundo tempo cirúrgico para revisão estética ${ }^{(3)}$. É importante salientar, que durante a confecção deste tipo de retalho, a lesão do ramo frontal do nervo facial é passível de acontecer, sendo importante manter um plano superficial de dissecção. A lamela posterior, em ambos os casos, foi reconstruída com a conjuntiva remanescente da fórnice, que foi suturada a face posterior do retalho.

Apesar de existir inúmeras técnicas para reconstrução palpebral descritas na literatura ${ }^{(1-3)}$, os autores acreditam que este tipo de retalho, pouco utilizado, deve ser levado em consideração, pois em alguns casos, é a única opção viável para a reconstrução.

\section{ABSTRACT}

Skin cancer is the most common neoplasm in human beings and among them, basal cell carcinoma is the most prevalent. This report shows two cases with this tumor, located in the lateral canthus, affecting both the superior and inferior eyelids. The first case was a female, 72 years old, with amaurosis of the right eye. One year ago, she noted a tiny papule at the left lateral canthus. The CT scan revealed that the tumor had compromised about $80 \%$ of the left superior eyelid, $70 \%$ of the inferior eyelid and showed superficial invasion of the lateral orbital wall. The histopathological test diagnosed basal cell carcinoma, with clear margins. The reconstruction of both eyelids was done with Fricke's flap. The second patient was a female, 68 years old, who had an accident with multiple scars at the left side of her face two years before. One year later, she noted a small lesion at the left side of the lateral canthus. The CT scan showed that the tumor had affected about $90 \%$ of the left superior eyelid, $65 \%$ of the inferior eyelid and showed superficial invasion of the lateral orbital wall. The histopathological test diagnosed basal cell carcinoma, with clear margins. The reconstruction of both eyelids was done with Fricke's flap. The authors belive that although this flap is not the first choice for a reconstructive procedure, it should not be forgotten because in some patients, it would be the only possible choice.

Keywords: Carcinoma, squamous cell/surgery; Skin neoplasms; Surgical flaps; Eyelids/surgery; Case reports [publication type]

\section{REFERÊNCIAS}

1. Stal S, Spira M. Basal and squamous cell carcinoma of the skin. In: Aston SJ, Beasley RW, Thorne CHM, Grabb WC, Smith JW, editors. Grabb and Smith's plastic surgery. Philadelphia: Lippincott-Raven; 1997. p.107-20.

2. Kwitko GM, Nesi FA. Eyelid and ocular adnexal reconstruction. In: Nesi FA, Levine MR, Lisman RD, editors. Smith's ophthalmic plastic and reconstructive surgery. Saint Louis: Mosby; 1998. p.582-607.

3. Mustardé JC. Repair and reconstruction in the orbital region. A practical guide. Edinburgh: Churchill Livingstone; 1980.

4. Preston DS, Stern RS. Nonmelanoma cancers of skin. N Engl J Med. 1992;327 (23):1649-62. Comment in: N Engl J Med. 2001;345(4):296; author reply 296-7.

5. Marks R, Jolley D, Dorevitch AP, Selwood TS. The incidence of non melanocytic skin cancers in an Australian population: results of 5 years prospective study. Med J. Aust. 1989;150(9):475-8.

6. Ishi LA, Pereira IC, Schellini SA, Marques MEA, Padovani CR. Carcinoma basocelular da pálpebra- fatores relacionados com a recidiva tumoral. An Bras Dermatol. 2004;79(4):423-30.

7. Pereira IC, Schellini AS, Silva MRBM, Marques MEA, Padovani CR. Aspectos do carcinoma basocelular da pálpebra na região de Botucatu (São Paulo). Rev Bras Oftalmol. 2000;59(10):737-43.

\section{Congresso Internacional da Sociedade Brasileira de Oftalmologia}

\section{0 a 22 de Julho de 2006}

\section{Hotel Glória}

\section{Rio de Janeiro - RJ}

Tel.: (21) 2557-7728

E-mail: sbo@sboportal.org.br 